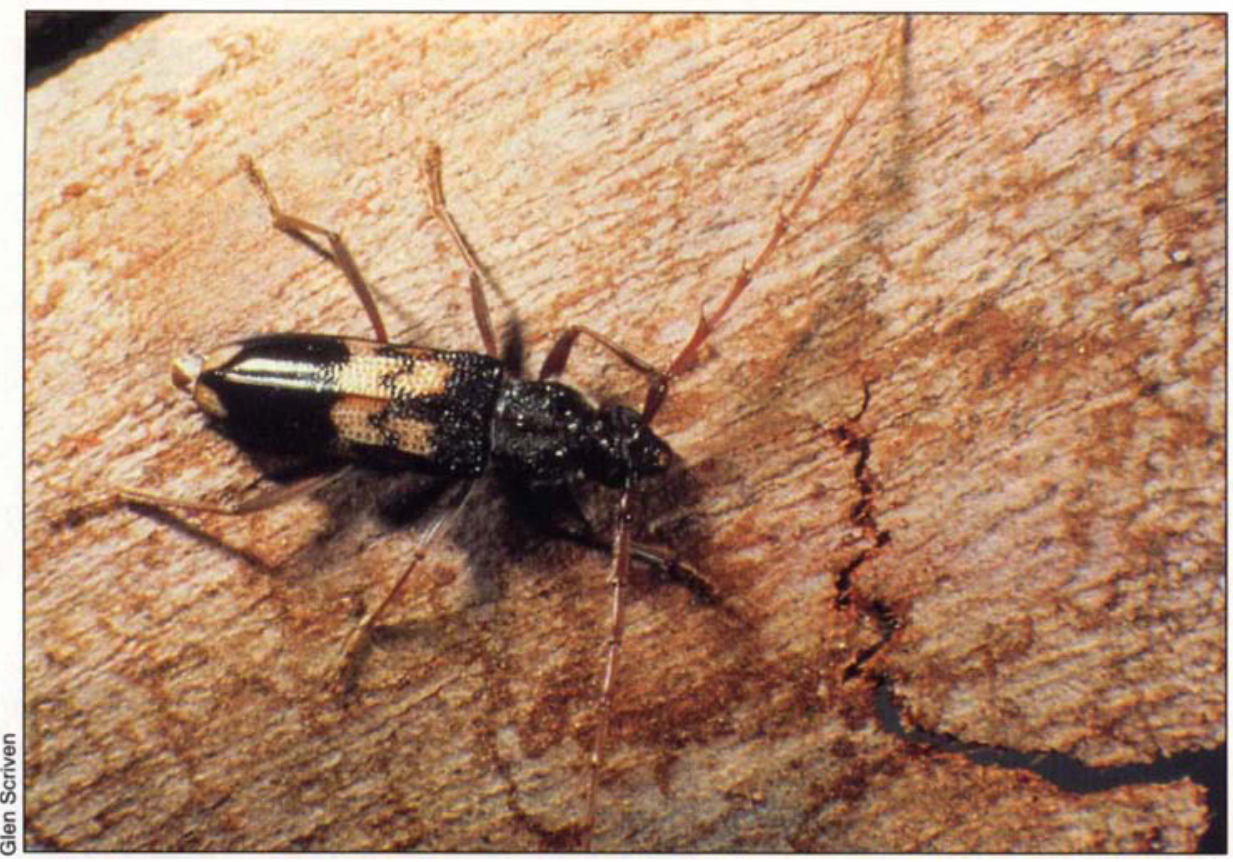

Adult beetles emerge from the tree and are attracted to new suitable host trees by volatile chemicals.

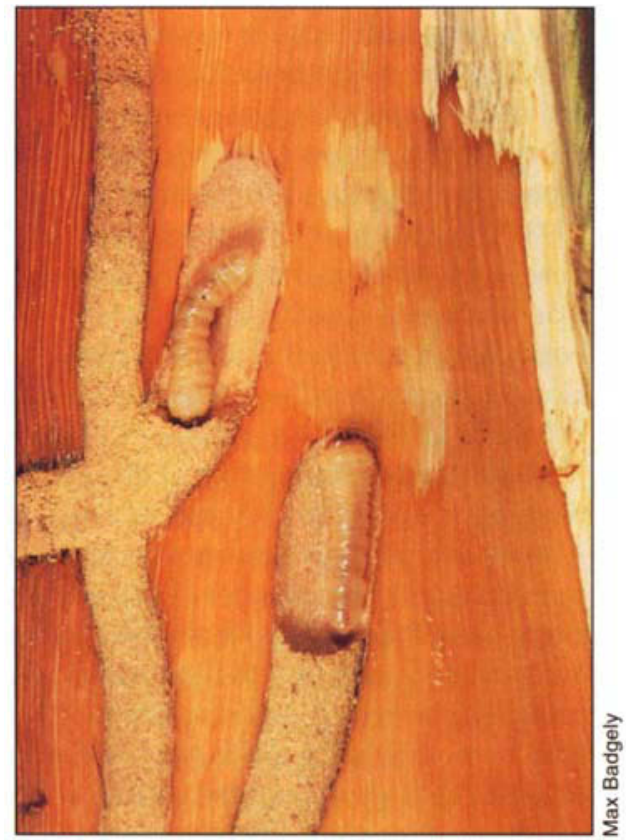

Larvae create galleries packed with excrement as they feed in the inner bark, phloem and outer xylem tissue of Eucalyptus hosts.

\title{
Integrated program protects trees from eucalyptus longhorned borer
}

\author{
Timothy D. Paine a J. G. Millar $\square \quad$ L. M. Hanks
}

\begin{abstract}
Phoracantha semipunctata $F$., $a$ cerambycid beetle introduced into California within the last 10 years, is killing large numbers of eucalyptus trees throughout much of the state. Risk of tree mortality can be reduced through managing tree stress, selection of more resistant tree species and disposal of infested wood. A biological control program to reduce beetle populations through the introduction of egg and larval parasites is currently being implemented. The combination of appropriate tree management and biological control holds promise for protecting these valuable ornamental tree species.
\end{abstract}

Eucalyptus species are native to Australia, but they have been planted in most of the world's temperate and tropical regions. The trees are valued for their vigor, tolerance of drought and poor soil conditions, and rapid growth rates. In many areas they are also resistant to most of the native herbivores and diseases. Consequently these trees usually require very little maintenance or management.

Eucalyptus trees were first planted in California at the turn of the century; there are now estimated to be more than 90 species in the state, as well as an unspecified number of varieties, subspecies and hybrids. At times vilified and at times glorified, eucalyptus trees have become prominent features in managed and unmanaged land- scapes, changing the face of California, especially in the southern half of the state. For example, Richard Henry Dana, in his classic book Two Years Before the Mast, described his travels in California in the early part of the 19th century, characterizing his first sight of the Los Angeles Basin as a barren, treeless plain. That barren plain has been transformed into a verdant urban landscape, in large part due to the introduction of Eucalyptus.Throughout the state, the value of eucalyptus trees and the cost of their replacement cannot be overestimated. They beautify the landscape and enhance the value of real estate. They also provide valuable shade to public and private buildings, decreasing the need for air conditioning in the heat of the summer. 


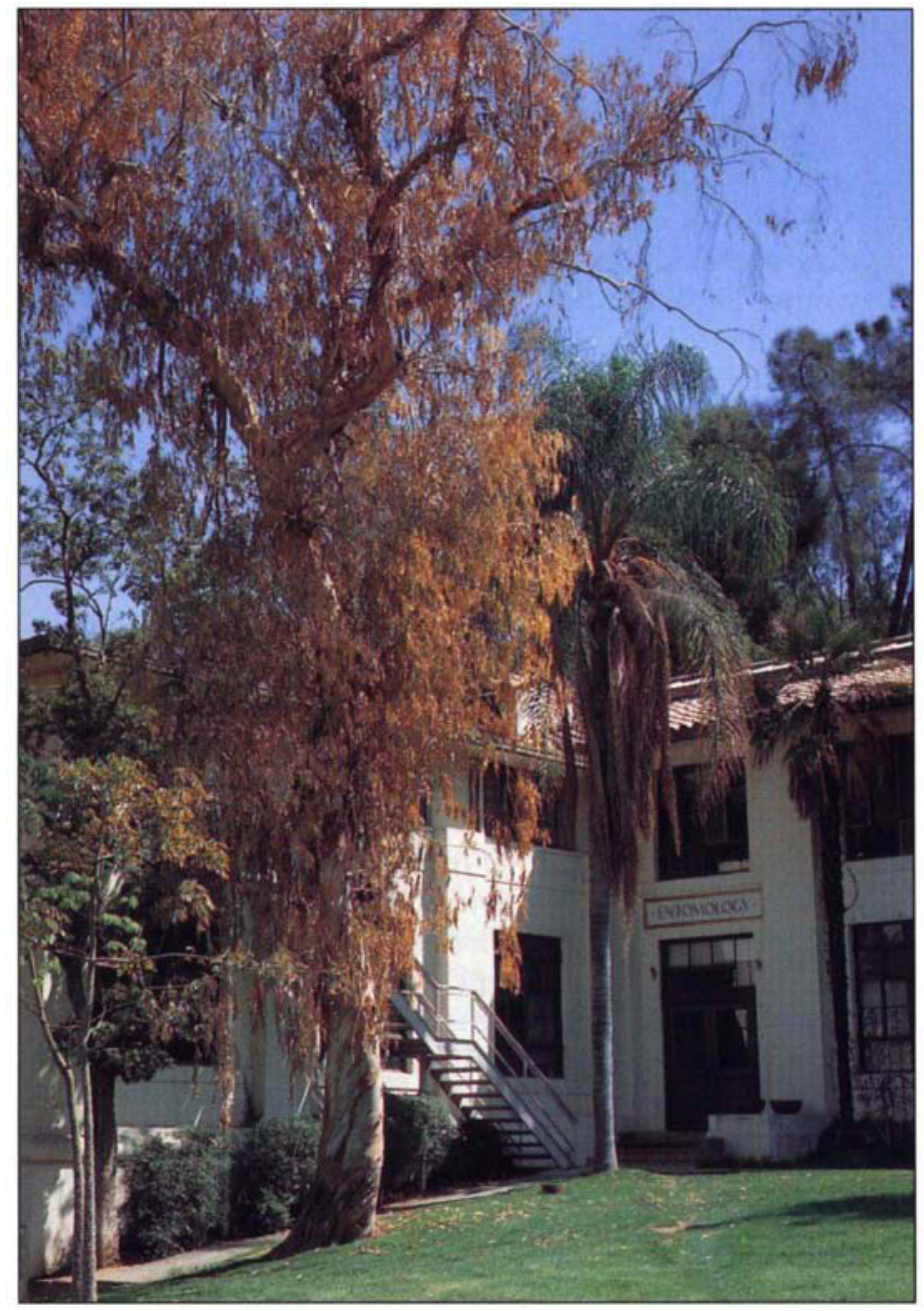

Healthy eucalyptus trees are important elements of the urban environment in California that contribute shade and architectural form to the landscape. Established landscape trees that are subjected to acute stress, as this tree was when the irrigation system failed for a period of several weeks, can be highly susceptible to beetle infestation.

Until recently, eucalyptus trees were especially valuable to California landscapes because they were free of insect pests. However, this situation has changed dramatically with the introduction of the eucalyptus longhorned borer (Phoracantha semipunctata), a cerambycid beetle. It is not clear how this insect was introduced into Southern California, but it arrived in the state sometime before 1985 (see California Agriculture July-August 1986). In its native Australia, the eucalyptus longhorned borer rarely kills healthy trees, utilizing instead broken limbs, logging residues, burned trees and highly stressed trees. However, in almost all areas of the world with Mediterranean climates where this beetle has been introduced, including California, it has rapidly become a pest, readily attacking and killing large numbers of eucalyptus trees.

Beetles are attracted to trees suffering from water stress, and unfortunately many of the most common Eucalyptus species planted in California are native to areas of Australia that have some moisture throughout the year. Although capable of growing in areas that do not receive precipitation in the summer, the trees are moisture stressed. The problem is exacerbated in California because many eucalyptus trees are growing in unmanaged or minimally managed environments with no supplemental irrigation. The large numbers of susceptible eucalyptus trees in these stressful environments are at risk of being killed by the beetle. The objective of our research on the Phoracantha-Eucalyptus system has been to develop an integrated management program to reduce the risk of tree mortality.

\section{Beetle history and distribution}

Adult beetles commonly begin to emerge from infested trees or logs in late spring, and emergence can continue for up to 16 weeks from individual brood logs. Males and females are attracted to suitable host material for oviposition by volatile chemical signals given off by logs and susceptible trees. Mating occurs on the bark, and females lay eggs under loose bark or in crevices on the bark surface. During her life span, a female may lay sev- eral batches of up to 40 eggs in each batch. If given a source of pollen and nectar for food, such as found in eucalyptus flowers, adult beetles can live more than 90 days.

Eggs hatch in 3 to 5 days. The first instar larvae mine very short distances in the outer bark layers before turning inward to mine at the inner bark-cambium-xylem interface. Larvae feed extensively in this tissue zone, effectively girdling the tree. Trees at this stage of infestation are characterized by thin, wilting or dry crowns with leaves remaining attached, cracked bark with packed larval excrement visible in the cracks, and often the clearly audible rasping sound of chewing beetle larvae. At the end of the feeding period, the larvae excavate pupal chambers in the wood. They enter the chambers, packing the holes behind them with wood shavings and excrement, or frass. Following pupation, the adult beetles emerge from the same holes by chewing through the plugs of frass. A beetle generation can take about 8 to 10 weeks during the summer and longer during the winter. Survivorship from egg to adult under field conditions can range up to $20 \%$.

Phoracantha semipunctata was first detected in Orange County, but populations are now continuously distributed throughout Southern California as far north as San Luis Obispo and Kern counties. Well-established populations are killing trees in Alameda, Santa Clara and San Mateo counties in the San Francisco Bay Area, and adult beetles have been reported in Sacramento. The disjunct statewide distributions may have resulted from movement of infested eucalyptus firewood, but this has not been confirmed. Within the next decade, the beetle will probably be distributed throughout the range of Eucalyptus in the state; the cooler temperatures in Central and Northern California will probably not adversely affect them. We determined this by holding logs with developing beetles at temperatures as low as $-5^{\circ} \mathrm{C}$ $\left(23^{\circ} \mathrm{F}\right)$ for up to 30 days. We found that these temperatures did not affect survivorship, but did delay adult emergence. Thus it appears that $P$. semipunctata will survive even in the 


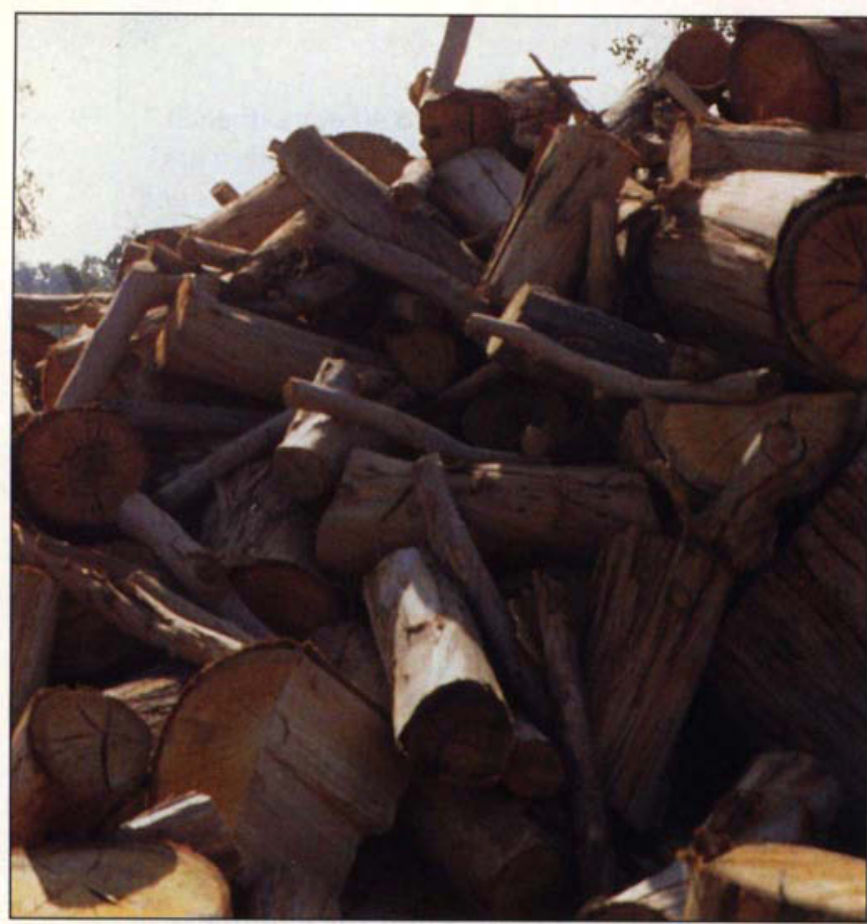

Destruction, disposal or treatment of infested trees and firewood is critical to reducing the probability of infestation of nearby trees.

northernmost plantings of Eucalyptus in California.

\section{Management of the environment}

Early work from both California and other regions of the world where $P$. semipunctata has become established demonstrates that insecticides are unsuitable for management of eucalyptus longhorned borer populations. Contact and systemic insecticide treatments are ineffective, costly or environmentally inappropriate because of the potential for drift, effects on beneficial or nontarget insects and risk of exposure to human populations in urban environments. Consequently, attention has been directed toward maintaining environmental conditions that favor the tree to the disadvantage of the beetle.

Tree care and reducing stressful conditions. Dark-brown gummy resin flowing from wounds in the bark of eucalyptus trees is sometimes, but not always, a sign that a tree is under attack by the eucalyptus longhorned borer. Some species of Eucalyptus are heavy producers of gum and other species produce much less. It appears that healthy trees may produce larger amounts than stressed trees, but there does not appear to be a direct relation- ship between gum production and resistance to the beetle. In fact, it appears that the moisture content of the spongy outer bark of Eucalyptus may be a much more critical factor in determining whether or not a tree will be successfully colonized. Young larvae are killed as they attempt to penetrate bark with high moisture content, but readily mine through drier bark. Thus trees under moisture stress are much more susceptible to attack.

Ironically, trees that have grown in wellwatered conditions but are suddenly subjected to water deficit seem to be at greater risk than trees that have always grown under limited moisture conditions. The trees that grow continually under more stressful conditions develop deeper root systems and utilize deep subsoil sources of moisture. Trees that receive frequent shallow irrigations, characteristic of urban landscape plantings, develop surface root systems and suffer acute water stress if irrigation is cut off, even for short periods. Consequently, those urban trees with the greatest economic value may be put at the greatest risk through improper water management.

In addition to water deficit, stresses associated with pruning may increase risk of infestation. Beetles are attracted to volatile chemicals associated with tree injury, and may be attracted to freshly pruned trees as well as to the cut branch and leaf residue from pruning. However, like water stress, this type of stress can be managed. The beetles usually are actively searching for oviposition sites from May to October. If tree trimming can be scheduled in months when beetles are not active, then the pruned trees will recover before beetles are present in large numbers, thereby minimizing the risk of tree death.

\section{Selection of the right tree spe-} cies. Selection of the right tree species for a specific location in the urban landscape is often a matter of aesthet- ics and availability. However, future pest problems, both insects and diseases, should be considered when a decision is made because the tree will become a long-lived feature of the environment and will be costly to remove or replace. Eucalyptus trees have been extensively planted in California because they are nondeciduous, have few pest problems, and have required minimal maintenance. There are Eucalyptus species with aesthetic qualities to fit a tremendously broad range of site requirements. Some of these species, particularly $E$. saligna, $E$. globulus, E. nitens, E. viminalis and $E$. diversicolor, are highly susceptible to eucalyptus longhorned borer. In contrast, E. robusta, E. sideroxylon, $E$. camaldulensis, E. cladocalyx, E. citriodora and $E$. trabutii appear to be relatively resistant. There are hundreds of species to choose from here and in Australia, but only a small fraction of these species have been evaluated for susceptibility to this insect. It is important to remember that even trees of a resistant species should be kept in vigorous condition. A tree of a susceptible species that is well cared for may be at less risk of infestation than a neglected tree of a resistant species.

\section{Removal of sources of beetles} through sanitation. Infested trees are a source of beetles for subsequent infestations. Infested trees that are cut down take on the appearance of firewood, but still contain many living larvae and pupae. Sanitation, the treatment or disposal of wood that contains larvae, pupae or adult beetles waiting to emerge, is critical for reducing beetle numbers and limiting the number of trees that are killed each year. Any action must occur before the new generation of adult beetles emerges. Methods of treatment include burning, burying, chipping or solarization (wrapping piles of cut wood in plastic exposed to direct sun for 10 to 12 weeks). Chipped eucalyptus wood makes excellent mulch, and solarized wood can be safely stored for firewood.

Care must also be taken with cut uninfested wood. Until the wood dries below a critical level, it remains suitable and highly attractive for oviposit- 
ing beetles. Anything that can be done to speed the drying process, such as cutting and splitting the wood, helps to reduce the length of time it can support beetle development. Removal of bark from freshly cut uninfested eucalyptus logs also prevents beetle infestation of the wood by reducing the available food and increasing the rate of drying of the wood. If the wood becomes infested, it should be treated or destroyed.

\section{Biological control}

Eucalyptus longhorned borer is relatively uncommon in Australia and rarely kills trees in native stands. In Australia, the borers are fed upon by a number of predaceous and parasitic insects that are also native to the continent. The deaths of large numbers of Eucalyptus around the world in areas where the beetle has been introduced may be partly explained by the absence of specific predators and parasites of the pest in those sites. Natural enemies reduce the number of borers in Australia, and we hope to achieve a similar reduction by introducing several species of parasites of $P$.

semipunctata into California.

Introduction of several parasites that specialize in different life stages of the beetle may increase the effectiveness of the biological control program. We have introduced a tiny wasp in the genus Avetianella from Australia that lays its eggs within the eggs of the beetle. Each female wasp lays up to 250 eggs during her 20-day adult life. We have conducted releases at nine sites in Southern and Northern California by taking parasitized eucalyptus longhorned borer eggs from the laboratory to the field release sites, placing them on freshly cut eucalyptus logs and allowing the parasite adults to emerge naturally in the field. The fresh logs are placed at these locations to attract ovipositing beetles, with the objective of having fresh beetle eggs available to the newly emerged wasps. Between July 1 and October 1, 1993, over 53,000 individuals of the egg parasite were released. The parasites have dispersed from the release sites; we have observed parasitized egg masses of the beetle at eight of nine sites and up to 10 miles distant from the release point.

We have also released or plan to release three species of braconid wasp parasites of eucalyptus longhorned borer larvae. Adults of two Jarra spp., Syngaster lepidus and Callibracon limbatus, are attracted to infested eucalyptus trees and use long egg-laying structures to drill through the bark and locate feeding beetle larvae. The female wasp parasites paralyze the developing larvae and lay one or more eggs on each one. These eggs hatch and the developing parasite larvae feed on the borer larvae, eventually killing them. Development of the immature stages of these parasites takes approximately 6 weeks. The adult wasps tunnel out through the bark to emerge, mate and search for new larval hosts. A total of approximately a thousand S. lepidus were released in 1993 at six sites throughout the state.

\section{Prospects for the future}

None of the natural enemies or the tree management strategies described here will eradicate the eucalyptus longhorned borer from California. Rather, populations of the borer and its natural enemies will coexist at lower stable levels and tree mortality should be reduced. Although the prospects for reducing current rates of damage and tree mortality caused by the beetle appear to be very good, this also means that some stressed or highly susceptible eucalyptus trees will still be killed by the beetle. It is critical that protection of valued urban tree species like Eucalyptus be viewed

\section{The introduction of natural enemies like the larval parasite, Syngaster lepidus, shown ovipositing through the bark, should result in lower beetle populations and lower levels of tree mortality.}

as part of a management system; reliance on a single control strategy is not likely to be entirely effective. Instead, implementation of a combination of environmentally safe and complementary strategies that integrate proper tree management, sanitation, selection of resistant tree species for new plantings and establishment of highly specific natural enemies for biological control holds the most promise for successfully managing this insect pest.

T.D. Paine and J.G. Millar are Associate Professors and L.M. Hanks is Assistant Research Entomologist in the Department of Entomology, UC Riverside.

The authors thank Rancho Santa Fe Association, Elvenia Slosson Fund for Ornamental Horticulture, California Department of Forestry and Fire Protection, California Department of Transportation, UC Statewide Integrated Pest Management Program, and California Association of Nurserymen for their support of this project. We also thank $P$. Svihra and $R$. Redak for their careful reviews of the manuscript, and F. Ameeri, J. Arredondo, S. Gilbert, J. Gould, K. Kund, S. McElfresh, D. Ott, T. Promlee, S. Rama and $A$. Rust for their contributions and assistance. 